\title{
Nursing interventions in transseptal catheterization
}

\section{Ivica Benko*, Gordana Hursa, Sanja Keleković, Dorotea Vuk}

University Hospital Centre "Sestre milosrdnice", Zagreb, Croatia
KEYWORDS: nursing, transseptal catheterization, transseptal puncture, complications

CITATION: Cardiol Croat. 2018;13(1-2):49. I https://doi.org/10.15836/ccar2018.49

*ADDRESS FOR CORRESPONDENCE: Ivica Benko, Klinički bolnički centar Sestre milosrdnice, Vinogradska cesta 29, HR-10000 Zagreb, Croatia. / Phone: +385-1-3787-312 / E-mail: ivica.benko@kbcsm.hr

ORCID: Ivica Benko, https://orcid.org/0000-0002-1878-0880 • Gordana Hursa, https://orcid.org/0000-0001-9118-9707 Sanja Keleković, https://orcid.org/0000-0003-4951-876X • Dorotea Vuk, https://orcid.org/ 0000-0003-0697-4730

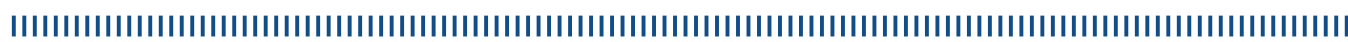

Transseptal catheterization is a procedure that allows transvenous access to the structures of the left heart but percutaneously and mostly via femoral veins. Transseptal catheterization has been primarily developed for the evaluation of valvular disease and mitral valvuloplasty, while today, transseptal approach is widely used in various interventions in invasive cardiology like left atrial appendage occluders, mitral balloon valvuloplasty, MitraClip, invasive evaluation of left atrial pressure, electrophysiology procedures, etc. Transseptal catheterization is performed by using specially designed needles, sheaths and dilatators. ${ }^{1-3}$

In University Hospital Centre "Sestre milosrdnice", transseptal catheterization is most frequently performed with Brockenbrough needle and Mullins sheath, and with help of coronary sinus catheter as an orientation for the transseptal puncture (TSP). Further orientation and control are performed wit use of fluoroscopy (in left anterior oblique - LAO 45, and right anterior oblique - RAO 30 projection) and use of invasive blood pressure. Like in any other invasive procedure, a thorough preparation is important to minimize the risk for complications. TSP is one of the procedures where nursing staff has a major influence on the rate of complications, from material preparation to assisting physician and monitoring of anticoagulant parameters.

In this paper, we are showing 5-year follow-up, where in 629 patients (441 male, 190 female) 1040 TSP were performed. Transseptal catheterization was mostly indicated for electrophysiology procedures. $90.4 \%$ of procedures were only guided with fluoroscopy and invasive pressure, while $9.6 \%$ needed additional guidance with transesophageal echocardiography. In these 629 patients, 3 perforations/tamponade $(0.4 \%)$ occurred, and were treated with percutaneous drainage. There were $4(0.6 \%)$ thromboembolic events: 2 transient ischemic attacks and 2 coronary events with changes in ST-segment. Since there is a constant increase in a number of transseptal catheterizations and it is becoming a standard procedure in catheterization labs, nursing staff must therefore be trained in for this kind of procedure and its complications.
RECEIVED:

February 4, 2018

ACCEPTED:

February 10, 2018

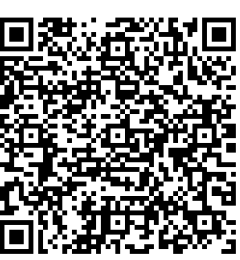

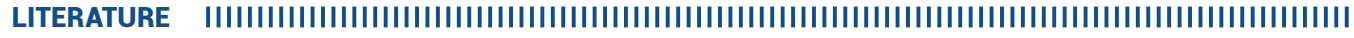

1. De Ponti R, Marazzi R, Picciolo G, Salerno-Uriarte JA. Use of a novel sharp-tip, J-shaped guidewire to facilitate transseptal catheterization. Europace. 2010 May;12(5):668-73. https://doi.org/10.1093/europace/euq060

2. Bayrak F, Chierchia GB, Namdar M, Yazaki Y, Sarkozy A, de Asmundis C, et al. Added value of transoesophageal echocardiography during transseptal puncture performed by inexperienced operators. Europace. 2012 May;14(5):661-5. https://doi.org/10.1093/europace/eur366

3. Pavlović N, Manola Š, Radeljić V, Benko I, Kühne M, Sticherling C. Transseptal catheterization. Cardiol Croat. 2014;9(3-4):127-33. Available at: http://www.kardio.hr/pdf/Cardiol\%20Croat_2014_9_3-4_127-133.pdf 